\title{
A didactic platform for the study of Linear Quadratic Regulator (LQR) control for Trajectory Tracking of dc motor
}

\section{Plataforma didáctica para el estudio del Regulador cuadrático lineal (LQR) para seguimiento de trayectoria en un motor DC}

HERNÁNDEZ-SANTIAGO, Joaquin† $\dagger$, ESCOBEDO-TRUJILLO, Beatris and GARRIDO, Javier

\author{
Universidad Veracruzana \\ ID $1^{\text {st }}$ Author: Joaquin, Hernández-Santiago / ORC ID: 0000-0003-1031-1016 \\ ID $1^{\text {st }}$ Co-author: Beatris, Escobedo-Trujillo/ ORC ID: 0000-0002-8937-3019, CVU CONACYT ID: 173174 \\ ID $2^{\text {nd }}$ Co-author: Javier, Garrido / ORC ID: 0000-0001-9143-408X, Researcher ID Thomson: C-9373-2018
}

\begin{abstract}
The main objective of this work is to show in detail the methodology to apply the Linear Quadratic Regulator (LQR) for Trajectory Tracking in an experimental way in a didactic platform which consists of a DC motor, the motor model is explained, and how the parameters were estimated experimentally and the validation thereofs. Results are shown applying the LQR control in simulation and experimentally.
\end{abstract}

\begin{abstract}
Resumen
El objetivo principal del presente trabajo es mostrar a detalle la metodología para aplicar el control LQR para el seguimiento de trayectorias de forma experimental en una plataforma didáctica la cual consiste en un motor de Corriente Directa (CD). Se explica el modelo del motor, y como se estimaron los parámetros de forma experimental y la validación de estos. Se muestran los resultados aplicando el control LQR en simulación y de manera experimental.
\end{abstract}




\section{Introduction}

The study of automatic control is necessary for the training of future engineers, PID control is the most common controller in the courses of the university and its laboratories have the equipment to carry out practices, but in the case of modern control, regulation system, optimal control, and in particular LQR control the practices generally is done in simulation, therefore in this work shows a prototype experimental to prove to the students how the LQR control is applied in DC motor.

The didactic platform consists of a Data Acquisition System (DAQ), a Human Interface Machine (HMI), sensor, powers supplies, and DC generator-motor, The HMI shows the current, angular velocity and the control signal of the DC motor, this data's can be stored for use after in Matlab software. The didactic platform control a DC motor, We can control torque, position, speed, and acceleration, only varying input voltage, for this reason, the design of the power stage is easy to design, the DC motor has a lot of applications in trains and electric cars (Gupta \& Deb, 2012), micro motors, robots (Zhou, 2008), mobile robots (Zhou, 2008) or as starting devices to drive compressors and elevators (Saraswathy, Paul, \& Mathew, 2018).

The PID controller for the DC motor is the most common, exist different combination for control of the DC (Taut, Chindris, \& Pitică, 2018), motor for example Neural network with PID, Fuzzy logic with PID (Arulmozhiyal \& Kandiban, 2012), this type of controller has the advantage it's only using the error for controlling the DC motor, but they have the disadvantage of not optimize of cost function, for example, if we wish to use minimum of energy or tracking control in settling time minimum, the controller PID must be tuned several times and try it in the system until the desired output is reached

The optimal control can make output follow to reference and minimize the cost function. The problem of optimal control deals with to modify the behavior of the dynamic system $x^{\prime}(t)=f(t, x(t), u(t))$ to reach an objective through of an control signal $u(t)$, and same time optimize some payoff function $f_{0}(t, x(t), u(t))$ which depends on the solution of dynamic system $x(t)$ and $u(t)$ (Geering, 2007).
There are works related to LQR controller in DC motor (Howimanporn, Chookaew, \& Sootkaneung, 2018), (Sahoo, Subudhi, \& Panda, 2015) y (Dani, Sonawane, Ingole, \& Patil, 2017) in the which the angular velocity of DC is controlled and the performance between LQR and PID are compared.

This work is organized as follows, in section 1. Linear Quadratic Regulator (LQR) for Trajectory Tracking of DC motor is presented, in section 2 the didactic platform is described, as well as, the model of motor, estimation, and validation of its parameters, in section 3 the simulation and the results of the experiment when applying the LQR controller are shown, Finally, the conclusions are presented.

\section{1.- LQR control for Trajectory Tracking}

The linear dynamic system has the following form

$$
x^{\prime}(t)=A x(t)+B u(t)
$$

The cost function to optimize is

$$
\begin{aligned}
& J\left(t_{0}, x, u\right)=\frac{1}{2} \int_{t_{0}}^{t_{1}}\left[x^{T}(t) Q x(t)+\right. \\
& \left.u^{T}(t) R_{C} u(t)\right] d t+x^{T}\left(t_{1}\right) S_{1} x\left(t_{1}\right)
\end{aligned}
$$

Where $S_{1}$ y $Q$ they are semi-definite positive matrices, whereas, $R_{C}$ is positive definite matrix.

The optimal control problem consists with finding a control $u^{*}(t)$ within a control compact set $U$ such that the cost $J\left(t_{0}, x, u\right)$ is minimal (Ogata, 2003) y (Geering, 2007). That is, a control is seek $u^{*}$ such that

$$
\begin{aligned}
& J^{*}\left(t_{0}, x\right)=J\left(t_{0}, x, u^{*}\right)= \\
& \min _{u \text { en } U} J\left(t_{0}, x, u\right)
\end{aligned}
$$

The function $J^{*}\left(t_{0}, x\right)$ is known the value function of optimal control problem, where $u^{*}(t)$ is the optimal control, the optimal strategy for the control problem is

$$
\begin{aligned}
& u^{*}(t)=-R_{C}^{-1} B^{T} P(t) x(t) \\
& u^{*}(t)=-K x(t)
\end{aligned}
$$

where $K=R_{C}{ }^{-1} B^{T} P(t)$, is the feedback gain, and $P(t)$ is the solution of the Riccati differential equation 


$$
\begin{aligned}
& P^{\prime}(t)+A^{T} P(t)+P(t) A- \\
& P^{T}(t) B R_{C}^{-1} B^{T} P(t)+Q=0
\end{aligned}
$$

The objective of LQR control is to take the state of process $x(t)$ from an initial condition $x\left(t_{0}\right) \neq 0$ to a final state with $x\left(t_{1}\right)=0$ with a cost minimum of some function that you want to minimize. When you want to take the initial state $x\left(t_{0}\right)$ to a final state $x\left(t_{1}\right) \neq 0$, you need to apply the integral action to the difference of the reference signal minus the system output, this ensures the error becomes zero and the output is equal to reference, this process is described below. The system is called augmented because one more state is added to the system, the solution of the state, $\xi^{\prime}(t)$. Here $\xi^{\prime}(t)$ is the difference between the reference signal minus the system output. From the system( $(I)$ the output is.

$$
y(t)=C x(t),
$$

The signal control is

$$
u(t)=-K x(t)+k_{I} \xi(t)
$$

Where

$$
\xi^{\prime}(t)=r(t)-y(t)=r-C x(t) .
$$

The system dynamic is described by a combination of $(1)$ and ( 8$)$ resulting in

$$
\begin{aligned}
& x^{\prime}(t)=A x(t)+B u(t), \\
& \xi^{\prime}(t)=r(t)-C x(t)
\end{aligned}
$$

In a matrix form

$$
\begin{aligned}
& {\left[\begin{array}{l}
x^{\prime}(t) \\
\xi^{\prime}(t)
\end{array}\right]=\left[\begin{array}{cc}
A & 0 \\
-C & 0
\end{array}\right]\left[\begin{array}{l}
x(t) \\
\xi(t)
\end{array}\right]+\left[\begin{array}{l}
B \\
0
\end{array}\right][u(t)]+} \\
& {\left[\begin{array}{l}
0 \\
1
\end{array}\right][r]}
\end{aligned}
$$

the optimal control is calculated as

$$
\begin{aligned}
& u^{*}(t)=-R_{C}{ }^{-1} \bar{B}^{T} P(t) \bar{x}(t) \\
& u^{*}(t)=K(t) \bar{x}(t)
\end{aligned}
$$

$$
\text { Where } \quad \bar{x}=\left[\begin{array}{l}
x^{\prime}(t) \\
\xi^{\prime}(t)
\end{array}\right], \quad K(t)=
$$
$-R_{C}{ }^{-1} \bar{B}^{T} P(t)$, and $\bar{B}=\left[\begin{array}{l}B \\ 0\end{array}\right]$. It is made up $(t)=\left[\begin{array}{ll}k & k_{i}\end{array}\right]$, and $P(t)$ the solution of the Riccati differential equation

$$
\begin{aligned}
& P^{\prime}(t)+\bar{A}^{T} P(t)+P(t) \bar{A}- \\
& P^{T}(t) \bar{B} R_{C}^{-1} \bar{B}^{T} P(t)+Q=0
\end{aligned}
$$

where $\bar{A}=\left[\begin{array}{cc}A & 0 \\ -C & 0\end{array}\right]$, the $\mathrm{LQR}$ control makes the states after a time worth zero, if apply to LQR to (9) the state $\xi^{\prime}(\infty)=0$, therefore, we obtain:

$0=r-y(\infty)$

$y(\infty)=r$

\section{Didactic platform for the LQR Control demonstration}

The didactic platform shows in the Fig.1, it is made up of the following elements: generatormotor, data acquisition system (DAQ), source voltage and computer, the DAQ is a compact RIO, was programmed using the LabVIEW software.

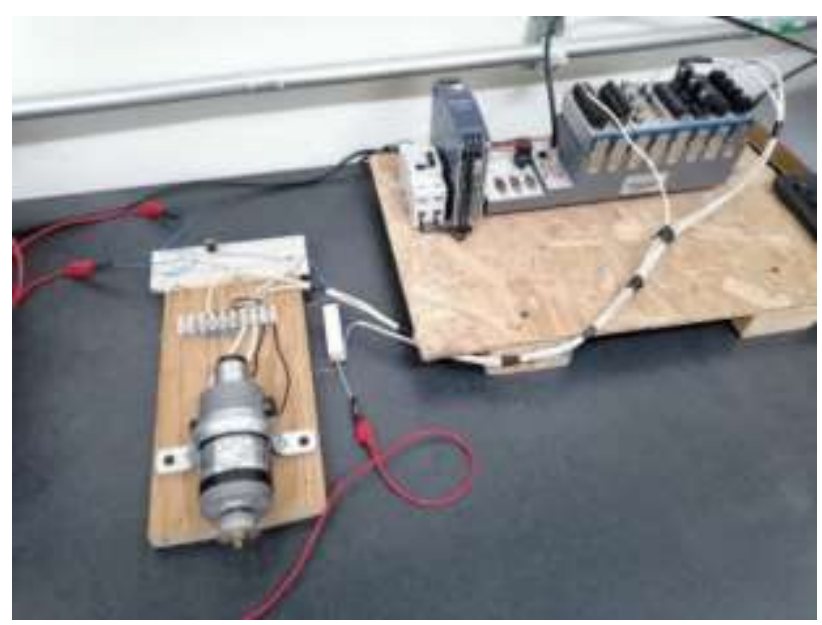

Figure 1 Dc motor and DAQ

The DAQ use a NI 9220, which is an analog input module for DAQ, each channel provides a $\pm 10 \mathrm{~V}$ measurement range at a 16-bit resolution. This module measures the motor voltage and voltage in the resistor $1 \Omega$, with which measure the current of the DC motor. NI 9220 measure the voltage of the generator coupled to DC motor, which is proportional to the angular velocity of the DC motor. In the Fig. 2 shows electric diagram. 


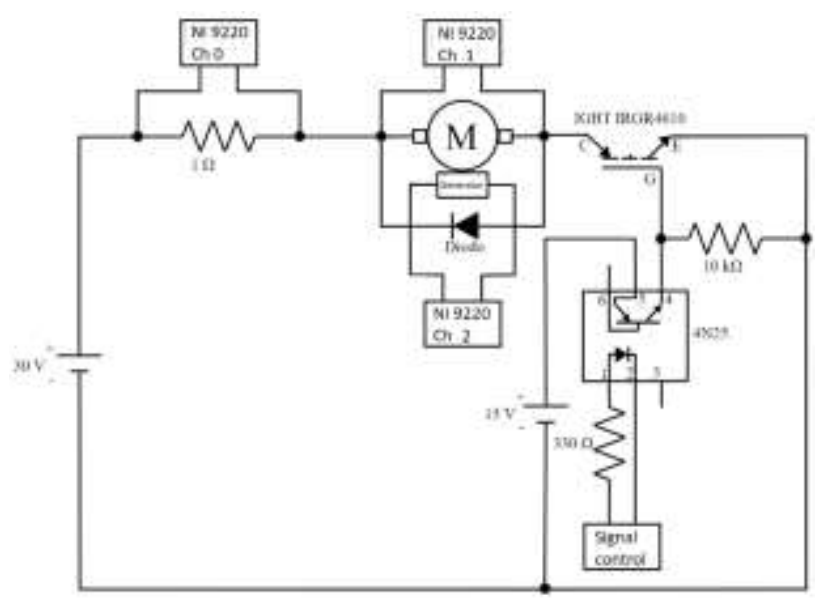

Figure 2 Electric diagram and drive control

The DC motor is coupled to a generator which produces a voltage that is proportional to the motor angular velocity. The DC motor-generator plate data are: voltage $=$ $\pm 30.8 \mathrm{~V}, \quad$ current $=3 \mathrm{~A}, \quad$ speed $=$ $4000 \mathrm{RPM}, \quad$ torque $=1.6 \mathrm{~N} / \mathrm{m} \quad$ and generated voltage $=7 \mathrm{~V} / 1000 \mathrm{RPM}$, the DC motor-generator is shows in the Fig. 3.

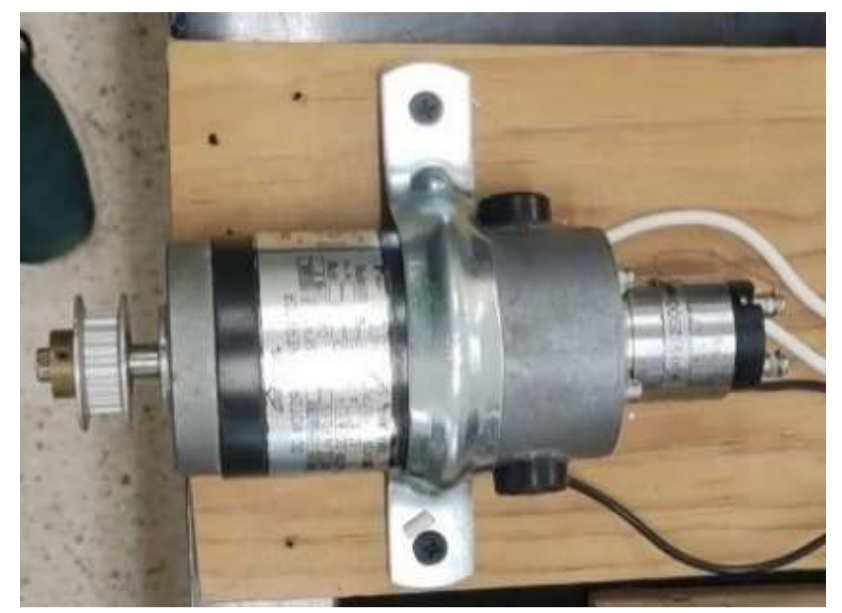

Figure 3 The DC motor-generator

The HMI can control turn on-off of DC motor, display the graphics of speed, current, DC motor Voltage and signal control. The HMI shows in the Fig. 4.

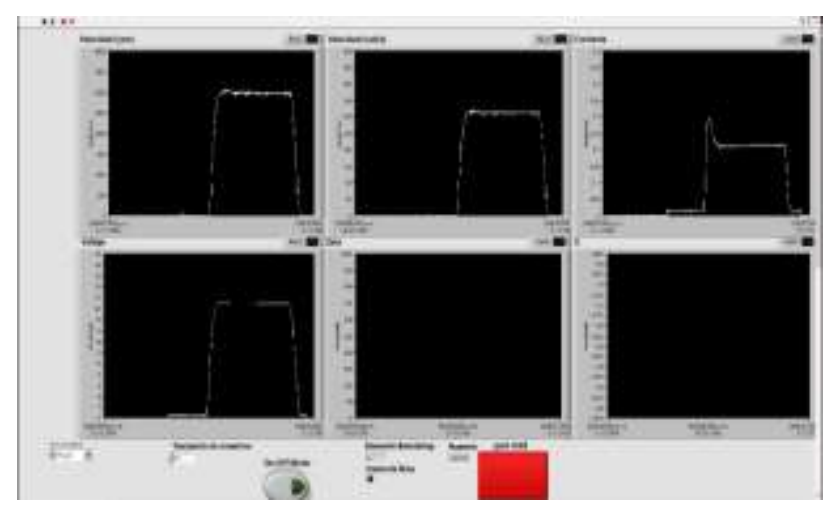

Figure 4 Human interface machine

ISSN-2444-5002

ECORFAN ${ }^{\circledR}$ All rights reserved
The LabVIEW program shows in the Fig. 5, the program calculates the signal control, to do this, the measures of sensors angular velocity and motor current are multiplied by the gain $\mathrm{k}$, the reference signal is generated and calculate the error, the result is multiplied by the gain $k_{i}$, finally both signals are added to generate the control signal $u(t)$.

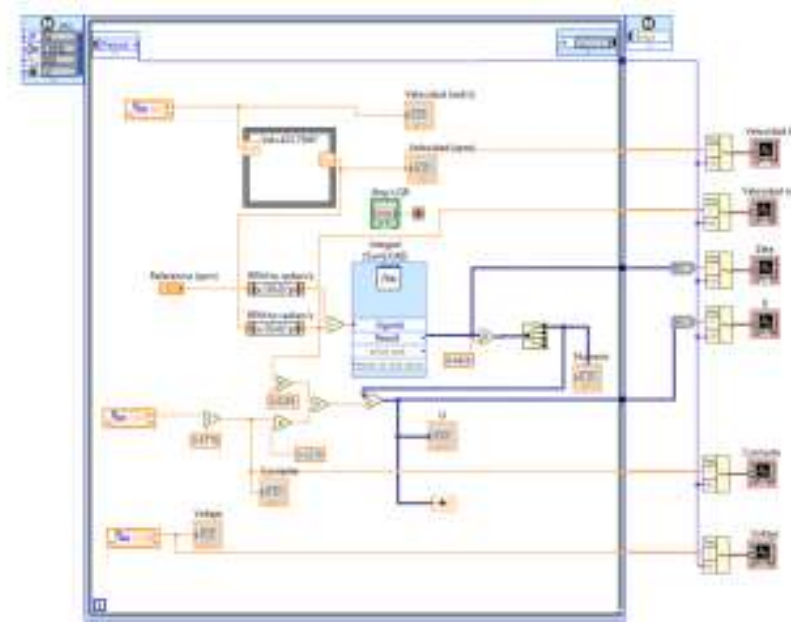

Figure 5 Labview Program

\subsection{Modelling of DC motor}

The electrical and mechanical diagram shows in Fig. 6 , the Table 1 shows the variables that were used to model the motor.

\begin{tabular}{|l|l|l|}
\hline Symbol & Variable & Units \\
\hline V & DC motor voltage & V \\
\hline I & Dc motor current & $\mathrm{A}$ \\
\hline $\mathrm{R}$ & Armature resistance & $\Omega$ \\
\hline $\mathrm{L}$ & Armature inductance & $\mathrm{H}$ \\
\hline$\omega$ & Angular velocity & $\mathrm{Rad} / \mathrm{seg}$ \\
\hline $\mathrm{J}$ & Rotor inertia & $\mathrm{Nm}^{2}$ \\
\hline $\mathrm{b}$ & Viscous friction coefficient & $\mathrm{N} / \mathrm{ms}^{-}$ \\
\hline$\tau_{\mathrm{f}}$ & Friction torque & $\mathrm{Nm}$ \\
\hline
\end{tabular}

Tabla 1 DC motor variables

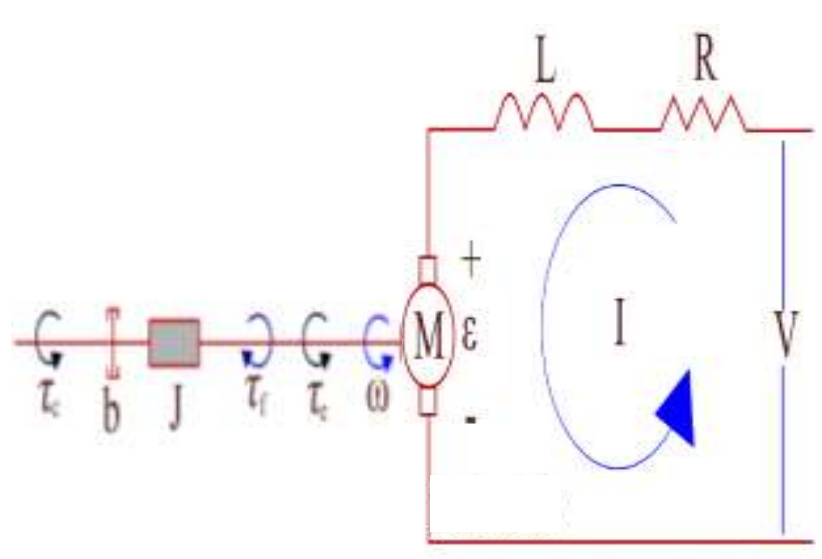

Figure 6 The electrical and mechanical diagram

HERNÁNDEZ-SANTIAGO, Joaquin, ESCOBEDO-TRUJILLO, Beatris and GARRIDO, JavierA didactic platform for the study of Linear Quadratic Regulator (LQR) control for Trajectory Tracking of dc motor. Journal of Computational Systems and ICTs. 2021 
The rotor of motor moves due to the electromagnetic torque $\tau_{e}$ generated by the magnetic field that is produced in the stator and depend on the current that circulates in the armature (Alvarez, 2012), its equation is

$$
\tau_{e}=k_{m} * I(t)
$$

where $k_{m}$ is the electromagnetic torque constant, the torque caused by friction that opposes the movement is

$$
\tau_{f}=\mathrm{b} * \omega(t)
$$

The motor in its rotary movement moves a load generating a resultant torque $\tau_{c}$ which is expressed as follows

$$
\sum \tau=\tau_{c}=J * \alpha=J * \frac{d \omega(t)}{d t}
$$

where $\alpha$ is the angular acceleration and can be expressed as the derivative of the angular speed. The sum of torques is as

$$
\tau_{c}=\tau_{e}-\tau_{f}-\tau_{s}
$$

where $\tau_{s}$ is a torque that represents the losses not considered and are represented by the function $m_{s}(t)$, substituting the equations (12) to (14) in (15)

$$
\frac{d \omega(t)}{d t}=-\frac{b}{J} \omega(t)+\frac{k}{J} I(t)-\frac{1}{J} m_{s}(t)
$$

By applying a voltage $\mathrm{V}$ to the armature, a current $I(t)$ circulates through the rotor, which generates force electromotive induced $\varepsilon$ which is calculated as $\varepsilon=k \omega(t)$, applying Kirchhoff's voltage law to the armature, we have

$$
-V(t)+R I(t)+L \frac{d I(t)}{d t}+\varepsilon=0
$$

Substituting the value of $\varepsilon$

$$
\frac{d I(t)}{d t}=-\frac{k}{L} \omega(t)-\frac{R}{L} I(t)+\frac{1}{L} V(t)
$$

The differential equations that describe a DC motor are (16) and (17), which can be written in a matrix form as.

$x^{\prime}(t)=A x(t)+B u(t)+G w(t)$ where $x$ is the state vector, $u$ is the control, $A, B$ and $\mathrm{G}$ are matrices of the form

$$
\begin{aligned}
& x^{\prime}(t)=\left[\begin{array}{c}
\frac{d \omega(t)}{d t} \\
\frac{d I(t)}{d t}
\end{array}\right], A=\left[\begin{array}{cc}
-\frac{b}{J} & \frac{k}{J} \\
-\frac{k}{L} & -\frac{R}{L}
\end{array}\right] \\
& x(t)=\left[\begin{array}{c}
\omega(t) \\
I(t)
\end{array}\right], B=\left[\begin{array}{ll}
0 & 0 \\
0 & \frac{1}{L}
\end{array}\right] \\
& u(t)=\left[\begin{array}{c}
0 \\
V(t)
\end{array}\right], G=\left[\begin{array}{cc}
-\frac{1}{J} & 0 \\
0 & 0
\end{array}\right] \\
& w(t)=\left[\begin{array}{c}
m_{s}(t) \\
0
\end{array}\right]
\end{aligned}
$$

\subsection{Estimation of DC motor parameters}

To estimate the DC motor parameters, the angular velocity $\omega(t)$, motor current $I(t)$ and motor voltage $V(t)$ are considered as variables, the parameters are: inductance and resistance, which will be measured directly; the parameters such as: viscous friction coefficient, moment of inertia and the motor constant will be calculated with (27), (28), the time constant $\tau$ is obtained experimentally.

The resistance and inductance were measured using an SKF Static Analyzer Baker Dx, the values are shown in table 2 . The motor constant $(\mathrm{k})$ is determined when the value of the current is constant $\left(\frac{d I(t)}{d t}=0\right)$, we obtain

$0=-k \omega(t)-R I(t)+V(t)$,

$k=\frac{V(t)-R I(t)}{\omega(t)}$

the viscous friction coefficient $b$ is calculated considering the angular velocity constant $\left(\frac{d \omega(t)}{d t}=0\right)$ it is despised $m_{s}$. Therefore, from (16) the following equation is reached

$0=-b \omega(t)+k I(t)$,

$b=\frac{k I(t)}{\omega(t)}$

The time constant $\tau$ is obtained by measuring the angular velocity $\omega(\mathrm{t})$ of DC motor when applying a constant voltage and measuring the time when reaches $63.21 \%$ of the final value. 
The angular velocity of the DC motor is shown in Fig. 7, the yellow line represents 3800 RPM, the blue line represents $63.21 \%$ of the final speed, therefore $\tau=0.56 \mathrm{~s}$. The moment of inertia is calculated as

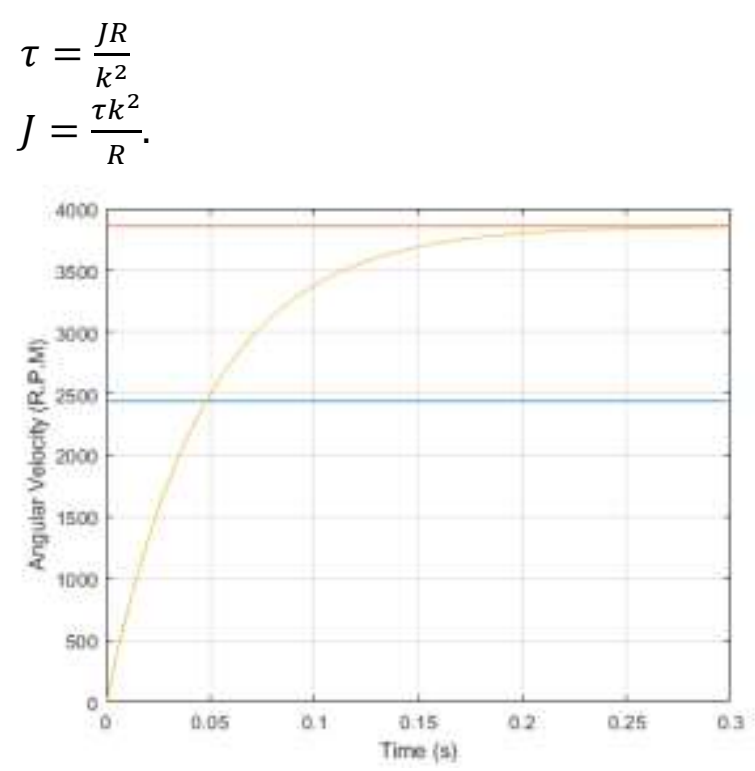

Figure 7 Angular velocity of DC motor

\subsection{Validation of DC motor parameters}

To validate the model and verify that the parameters, the motor was simulated with the parameters in Table 2, with a constant input voltage $V_{\text {in }}=28 \mathrm{~V}$, the same voltage was applied experimentally to the dc motor, in Fig. 8 the simulated graph and the measured graph of the angular velocity are observed.

\begin{tabular}{|c|c|}
\hline Variable & Valor \\
\hline $\mathrm{b}$ & $33.087 \mu N s / m$ \\
\hline $\mathrm{J}$ & $11.414 \mu \mathrm{Nm}^{2}$ \\
\hline $\mathrm{k}$ & 0.0504 \\
\hline $\mathrm{R}$ & $12.4522 \Omega$ \\
\hline $\mathrm{L}$ & $2.6 \mathrm{mH}$ \\
\hline
\end{tabular}

Tabla 2 Parámetros del motor obtenidos experimentalmente

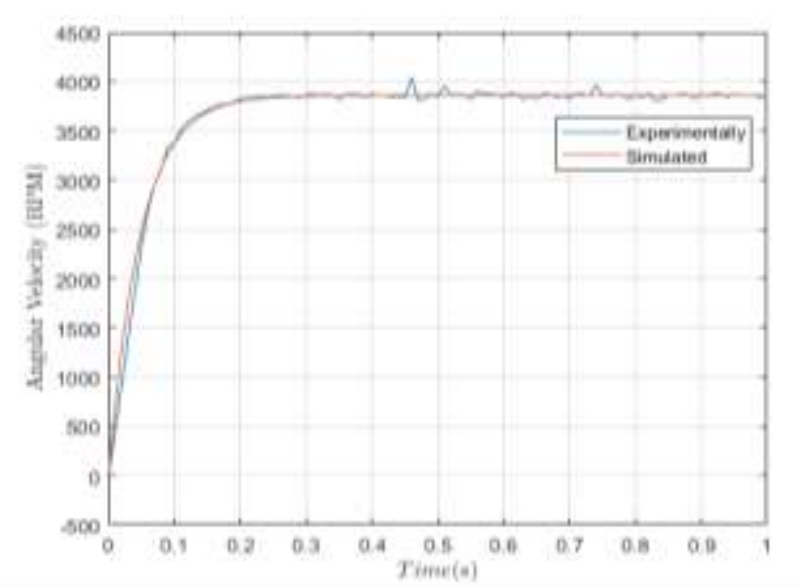

Figure 8 Angular velocity of DC motor in simulation and experimental

ISSN-2444-5002

ECORFAN ${ }^{\circledR}$ All rights reserved

\section{Experimental and simulation results}

The LQR controller for trajectory tracking was applied to the didactic prototype in simulation with Matlab software and experimentally.

The control signal $u^{*}(t)$ is calculate with (10), where the value of $\mathrm{Q}$ is a identity matrix, $R_{c}=100, K=[0.07870 .0719]$ y $k_{I}=$ 0.1 , the reference signal is $r=2000 R P M$. The angular velocity of DC motor is shown in the Fig. 9 and it is verified that it follows the reference in $0.8 \mathrm{~s}$. The control signal is shown in Fig. 10.

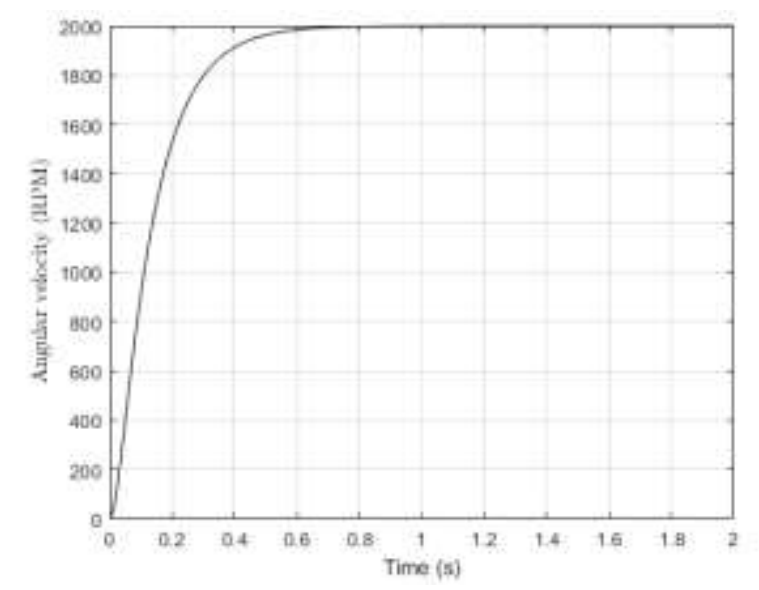

Figure 9 The angular velocity simulated with LQR control

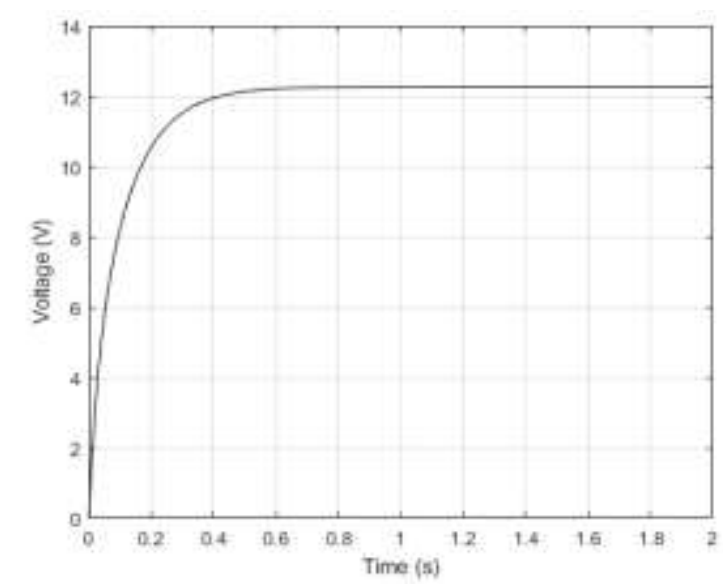

Figure 10 The control signal $u^{*}(t)$

The Figures 11 and 12 shows the graph's velocity angular, current and voltage of DC motor obtained by applying the LQR control to the didactic prototype. The reference signal is $=$ $3800 R P M$ which is reached in $t=0.8 \mathrm{~s}$, the current and voltage are below the nominal values of the DC motor 


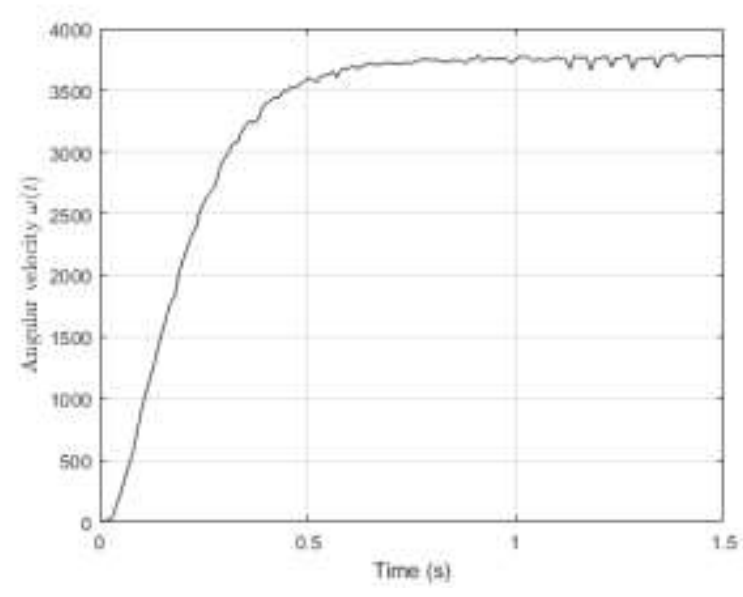

Figure 11 The angular velocity applying the LQR control to the didactic prototype
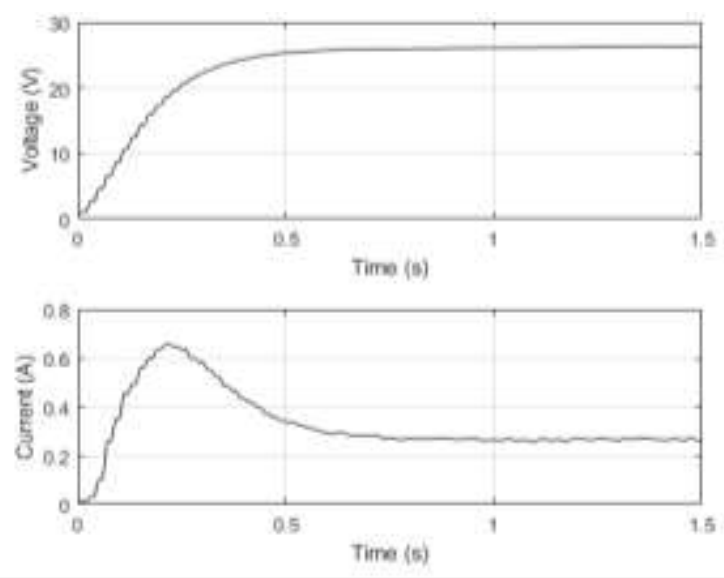

Figure 12 a) Voltage and b) Current of DC motor

\section{Conclusions}

This work presented the design of a didactic platform for the study of LQR control for trajectory tracking in a DC motor, the objective is to control the angular velocity and bring it to a reference position in real time was achieved. LQR controllers are generally applied in simulation, one of the goals of this work is to show the methodology that was used to be able to apply the LQR control experimentally in a DC motor.

Simulation of the LQR control was carried out with Matlab software obtaining results similar to those obtained experimentally, in both cases it was verified that the angular velocity of the dc motor follows the reference signal in a finite time and with a control signal within the voltage parameters that the motor supports.

\section{References}

Alvarez, M. S. (2012). Modelo matemático de un motor de corriente continua separadamente excitado: Control de velocidad por corriente de armadura. Guayaquil: Escuela Superior Politécnica de Litoral (ESPOL).

Arulmozhiyal, R., \& Kandiban, R. (2012, 10-12 Jan. 2012). Design of Fuzzy PID controller for Brushless DC motor. Paper presented at the 2012 International Conference on Computer Communication and Informatics.

Dani, S., Sonawane, D., Ingole, D., \& Patil, S. (2017, 7-9 April 2017). Performance evaluation of PID, LQR and MPC for DC motor speed control. Paper presented at the 2017 2nd International Conference for Convergence in Technology (I2CT).

Geering, H. P. (2007). Optimal Control with Engineering Applications: Springer Berlin Heidelberg.

Gupta, V., \& Deb, A. (2012, 4-8 March 2012). Speed control of brushed DC motor for low cost electric cars. Paper presented at the 2012 IEEE International Electric Vehicle Conference.

Howimanporn, S., Chookaew, S., \& Sootkaneung, W. (2018, 15-17 Sept. 2018). Implementation of PSO Based Gain-Scheduled PID and LQR for DC Motor Control Using PLC and SCADA. Paper presented at the 2018 International Conference on Control and Robots (ICCR).

Ogata, K. (2003). Ingeniería de control moderna: Pearson Educación.

Sahoo, S., Subudhi, B., \& Panda, G. (2015, 1213 June 2015). Optimal speed control of DC motor using linear quadratic regulator and model predictive control. Paper presented at the 2015 International Conference on Energy, Power and Environment: Towards Sustainable Growth (ICEPE).

Saraswathy, K., Paul, F. M., \& Mathew, A. (2018, 6-10 Jan. 2018). Four quadrant operation of BLDC motor suitable for DC micro grid for elevator application. Paper presented at the 2018 International Conference on Power, Signals, Control and Computation (EPSCICON). 
Taut, M. A., Chindris, G., \& Pitică, D. (2018, 25 28 Oct. 2018). PID Algorithm used for DC Motor Control. Paper presented at the 2018 IEEE 24th International Symposium for Design and Technology in Electronic Packaging (SIITME).

Zhou, H. (2008, 20-22 Oct. 2008). DC Servo Motor PID Control in Mobile Robots with Embedded DSP. Paper presented at the 2008 International Conference on Intelligent Computation Technology and Automation (ICICTA). 